\title{
Binding Properties and Structural Predictions of Homeodomain Proteins CDX1/2 and HOXD8
}

\author{
So Young Park, ${ }^{\text {a }}$ Mi Suk Jeong, ${ }^{a}$ and Se Bok Jang ${ }^{*}$ \\ Department of Molecular Biology, College of Natural Sciences, Pusan National University, Busan 609-735, Korea \\ *E-mail: sbjang@pusan.ac.kr
}

Received March 4, 2011, Accepted May 27, 2011

\begin{abstract}
Human CDX1 and CDX2 genes play important roles in the regulation of cell proliferation and differentiation in the intestine. Hox genes clustered on four chromosomal regions (A-D) specify positional signaling along the anterior-posterior body axis, including intestinal development. Using glutathione S-transferase (GST) pulldown assays, molecular interaction measurements, and fluorescence measurements, we found that the homeodomains (HDs) of CDX1 and CDX2 directly interact with that of HOXD8 in vitro. CDX1 showed significant affinity for HOXD8, but CDX2 showed weak affinity for HOXD8. Thus far, three-dimensional structures of CDX1/2 and HOXD8 have not been determined. In this study, we developed a molecular docking model by homology modeling based on the structures of other HD members. Proteins with mutations in the HD of CDX1 (S185A, N190A, T194A, and V212A) also bound to the HD of HOXD8. Our study suggests that the HDs of CDX1/2 resemble those of HOXD8, and we provide the first insight into the interaction between the HDs of CDX1/2 proteins and those of HOXD8.
\end{abstract}

Key Words : CDX1/2, HOXD8, Interaction, Mutations

\section{Introduction}

Cdx1 and Cdx2, mammalian homologs of the Drosophila caudal gene, are mainly expressed in the intestine and colon, where they appear to be involved in the regulation of cell proliferation and differentiation. ${ }^{1} \mathrm{Cdx} 1$ expression is restricted to the proliferative crypt compartment, whereas high levels of $\mathrm{Cdx} 2$ expression are found in the differentiated cells of the villus tip. The targets of $\mathrm{Cdx} 2$ include the HoxC8 homeobox gene, small intestinal genes encoding sucraseisomaltase, lactase-phlorizin hydrolase, phospholipase-A, calbindin-D9K, the colonic gene for carbonic anhydrase I, and the genes encoding insulin and glucagon in the pancreas. $^{2-7}$ All of these genes are differentiation-related, and support the tumor suppressive function of $\mathrm{Cdx} 2$ by inhibiting proliferation. ${ }^{3,4}$ In the case of Cdx1, only Hox-A7 has been shown to be a direct target. ${ }^{8}$

Hox genes encode transcriptional factors that specify regional identities along the embryonic axes of various organisms. ${ }^{9}$ In higher vertebrates, Hox genes have evolved into four clusters $(\operatorname{Hox} A, \operatorname{Hox} B, \operatorname{Hox} C$, and $\operatorname{Hox} D)$ by tandem duplication from a single ancestral cluster. ${ }^{10}$ Deregulation and chromosomal translocation in developmental genes in human cancers strongly suggest a role in oncogenesis. ${ }^{11}$ Human HOXB6, B8, C8, and C9 show overexpression in various stages of human colorectal cancers, including the development of premalignant polyps, as well as in several types of esophageal and gastric tumors. ${ }^{12}$ Similar to colorectal cancer cells, Caco-2 and HT-29 colon cancer cell lines show coordinated inverse regulation bet-

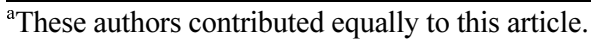

ween the expression of $\mathrm{HOXB} 6, \mathrm{~B} 8, \mathrm{C} 8$, and $\mathrm{C} 9$ and that of Cdx-1. ${ }^{13}$

The CDX1/2 genes have both common and specific cellular effects. Although both trigger cellular differentiation, CDX1 stimulates proliferation in cell cultures while CDX2 decreases it. ${ }^{14,15}$ They are also differentially targeted by regulatory pathways; for example, CDX1 is directly upregulated by $\mathrm{Wnt} / \beta$-catenin signaling, which is most active in the crypt compartment, whereas CDX2 is indirectly down regulated by this pathway. ${ }^{16,17}$ Recent studies have reported that, outside the gut, the CDX1 and CDX2 proteins have different effects on gene promoters involved in early embryonic development. ${ }^{18}$ Given these effects, it is important to delineate the specific molecular functions of CDX1 and CDX2.

To elucidate the mutual relationships between human CDX and HOX in signal transduction pathways, we investigated the interactions between the recombinant homeodomains (HDs) of CDX1/2 and HOXD8. Using several biochemical and biophysical assays, we demonstrated a direct protein-protein interaction between CDX1/2 and HOXD8.

\section{Materials and Methods}

Protein Cloning, Expression, and Extraction. HDs of CDX1 (152-216), CDX2 (184-248), and HOXD8 (203-256) were subcloned into the C-terminal His-tagged fusion protein vector $\mathrm{pET}-26 \mathrm{~b}$ for purification. $\mathrm{CDX} 1$ and $\mathrm{CDX} 2$ were amplified by polymerase chain reaction (PCR), using oligonucleotides incorporating $\mathrm{NdeI}$ and $\mathrm{XhoI}$ sites on the 5' primer and 3' primer containing a stop codon. 
CDX1 (152-216), 5'-GGAATTCCATATGCGGACCAAGGACAAGTA-3' and 5'-CCGCTCGAGTTTCTTCTTGTTCACTTTG-3'; CDX2 (184-248), 5'-GGAATTCCATATGAGGACGAAAGACAAATA-3' and 5'-CCGCTCGAGCTTCTTCTTGTTGATTTTC-3'; HOXD8 (203-256), 5'-GGAATTCCATATGACCTACAGTCGCTTCCA-3' and 5'-CCGCTCGAGGTTTTCCTTTTTCCATTTC-3'

Then, the HDs of CDX1 (152-216), CDX2 (184-248), and HOXD8 (203-256) were subcloned into a glutathione Stransferase (GST)-fused protein vector pGEX-4T1 for pulldown experiment. CDX1 and CDX2 were amplified by performing PCR with oligonucleotides incorporating EcoRI and $\mathrm{XhoI}$ sites on the $5^{\prime}$ primer and $3^{\prime}$ primer containing a stop codon.

CDX1 (152-216), 5'-GGAATTCATGCGGACCAAGGACAAGTA-3' and 5'-CCGCTCGAGTTATTATTTCTTCTTGTTCACTTTGCG-3'; CDX2 (184-248), 5'-GGAATTCATGAGGACGAAAGACAAATATCG-3' and 5'-CCGCTCGAGTTATTACTTCTTCTTGTTGATTTT-3'; HOXD8 (203256), 5'-CCGGAATTCACCTACAGTCGCTTCCA-3' and 5'-CCGCTCGAGGTTTTCCTTTTTCCATTTC-3'.

The sequences of the double-stranded oligonucleotides for site-directed mutagenesis of four different residues in CDX1 to alanine were as follows:

S185A, 5'-ATCCGGCGGAAAGCAGAGCTGGCTGCCAAT-3' and 5'-ATTGGCAGCCAGCTCTGCTTTCCGCCGGAT-3'; N190A, 5'-GAGCTGGCTGCCGCTCTGGGGCTCACTGA-3' and 5'-TCAGTGAGCCCCAGAGCGGCAGCCAGCTC-3'; T194A, 5'-AATCTGGGGCTCGCTGAACGGCAGGTGAAG-3' and 5'-CTTCACCTGCCGTTCAGCGAGCCCCAGATT-3'; V212A, 5'-AAGGAGCGCAAAGCGAACAAGAAGAAACAG-3' and 5'-GCTGTTTCTTCTTGTTCGCTTTGCGCTCCTT-3'

The plasmids with positive CDX1, CDX2, and HOXD8 expression were identified by restriction endonuclease digestion and further verified by DNA sequencing using a Macrogen automatic DNA sequencer. The constructs were transformed into the expression host Escherichia coli BL21 (DE3). A single colony was inoculated into $20 \mathrm{~mL}$ of LuriaBertani (LB) medium containing $50 \mu \mathrm{g} / \mathrm{mL}$ of ampicillin, and the bacteria were grown at $37^{\circ} \mathrm{C}$ overnight. These cells were then added to four 2-L flasks, each containing $500 \mathrm{~mL}$ of $\mathrm{LB}$ and $50 \mu \mathrm{g} / \mathrm{mL}$ of ampicillin. The cultures were grown at $37{ }^{\circ} \mathrm{C}$ until an $\mathrm{OD}_{600}$ of 0.5 was reached. The expression of these proteins was induced with $0.5 \mathrm{mM}$ isopropyl-thio- $\beta$ D-galactopy ranoside (IPTG). Bacterial cells were induced for $5 \mathrm{~h}$ at $25{ }^{\circ} \mathrm{C}$, and then harvested by centrifugation at $3,830 \times \mathrm{g}$ for $25 \mathrm{~min}$. The cell pellets were either used immediately or stored frozen at $-70^{\circ} \mathrm{C}$.

The CDX1, CDX2, and HOXD8 cell pellets were then resuspended in lysis buffer A $(50 \mathrm{mM}$ Tris- $\mathrm{HCl}$ with a $\mathrm{pH}$ of 7.5, $200 \mathrm{mM} \mathrm{NaCl}$, and $1 \mathrm{mM}$ dithiothreitol (DTT)). After sonication of the cell suspensions on ice (Branson Sonifier 450 ), the resulting cell lysates were centrifuged at $20,017 \times \mathrm{g}$ for $45 \mathrm{~min}$ to remove insoluble cellular debris. The insoluble fractions were directly resuspended in 2x sodium dodecyl sulfate (SDS) loading buffer, followed by incubation at 95 ${ }^{\circ} \mathrm{C}$ for $5 \mathrm{~min}$. The soluble and insoluble fractions were fractionated on $15 \%$ SDS-polyacrylamide gel electrophoresis (SDS-PAGE) gels and visualized by Coomassie blue staining. The supernatants were collected and used for protein purification.

Purification. His-tagged fusion proteins of CDX1/2 and HOXD8 were applied to a Ni-NTA (Amersham Pharmacia Biotech) column for purification. The supernatants obtained from the protein extraction step were loaded onto the $\mathrm{Ni}$ NTA column and pre-equilibrated with buffer A. The column was washed with buffer A containing imidazole, and elution of the bound proteins was achieved by varying the amount of imidazole (20-200 mM). Protein elution was monitored at $280 \mathrm{~nm}$, and the resulting fractions were analyzed via $15 \%$ SDS-PAGE. Then, gel filtration was performed using a highperformance liquid chromatography (HPLC) system with a Superdex 75 column. The proteins were loaded onto the column equilibrated with buffer $\mathrm{A}$ and were separated at a flow rate of $1.5 \mathrm{~mL} / \mathrm{min}$.

The clear CDX1/2 supernatants were loaded onto Glutathione-Sepharose 4 Fast Flow (Amersham-Pharmacia Biotech; binding capacity of $10 \mathrm{mg}$ of GST per milliliter of resin) at a flow rate of $2.5 \mathrm{~mL} / \mathrm{min}$ and were washed extensively with $20 \mathrm{~mL}$ of phosphate-buffered saline (PBS) buffer. The GST-HOXD8 fusion protein was eluted with 10 $\mathrm{mL}$ of $10 \mathrm{mM}$ reduced glutathione dissolved in $50 \mathrm{mM}$ Tris$\mathrm{HCl}$. The eluted fraction was dialyzed against elution buffer for $12 \mathrm{~h}$ at $4{ }^{\circ} \mathrm{C}$. The reaction mixture was then loaded at 2.5 $\mathrm{mL} / \mathrm{min}$ onto a Q-Sepharose Fast-Flow (Amersham-Pharmacia Biotech) anion exchange chromatography column pre-equilibrated with buffer A. Elution was performed using the salt gradient of the $\mathrm{NaCl}$ solution. The protein was passed through the Q-Sepharose column to remove cellular DNA and negatively charged acidic proteins. The CDX1/2 proteins were then concentrated by centrifugation at $2,500 \mathrm{rpm}$ using ultrafiltration devices to a final volume of $10 \mathrm{~mL}$. Then, gel filtration was performed using a Superdex 75 HPLC column.

Western Blotting. The purified CDX1/2 and HOXD8 proteins from $15 \%$ SDS-PAGE analysis were transferred onto a nitrocellulose membrane at $115 \mathrm{~V}$ for $1 \mathrm{~h}$. The membrane was blocked for $2 \mathrm{~h}$ with $5 \%$ skim milk in Tween-PBS buffer containing $1 \%$ Tween 20 . The membrane was then incubated with primary antibody (His-probe (G18) diluted 1:1000; Santa Cruz Biotechnology, Inc.) for $12 \mathrm{~h}$. After washing with Tween-PBS, the membrane was incubated for $1 \mathrm{~h}$ with goat anti-rabbit IgG-HRP secondary antibody (Santa Cruz Biotechnology, Inc.) diluted at a ratio of $1: 10,000$ in blocking buffer.

Matrix-Assisted Laser Desorption/Ionization Mass Spectrometry (MALDI-MS). For in-gel digestion, $10 \mu \mathrm{L}$ of trypsin solution $(2 \mathrm{ng} / \mathrm{L}$ in $25 \mathrm{mM}$ ammonium bicarbonate with a pH of 8.0) was added and digested overnight at $37^{\circ} \mathrm{C}$. Peptides were extracted with a solution of $50 \%(\mathrm{v} / \mathrm{v})$ aceto- 
nitrile (ACN) and $0.2 \%$ trifluoroacetic acid (TFA) and then dried under vacuum for $2 \mathrm{~h}$, followed by reconstruction with $3 \mu \mathrm{L}$ of $\alpha$-cyano-4-hydroxycinnamic acid (CHCA) matrix solution (8 mg of CHCA in $1 \mathrm{~mL}$ of $50 \%$ (v/v) ACN $/ 0.2 \%$ TFA). One microliter of the reconstructed sample was then loaded onto a $96 \times 2$ MALDI plate. The peptide mass was acquired using the Voyager DE-PRO biospectometry workstation (Applied Biosystems, Framingham, MA) in reflector mode under $20,000 \mathrm{~V}$ of accelerating voltage, $76 \%$ grid voltage, and $0.002 \%$ guide-wire voltage. Cal Mix 2 from the MALDI-MS calibration kit (Applied Biosystems, Framingham, MA) was used for external calibration, and autolysis fragments of trypsin were used for internal calibration. Peptide matching and protein identification were performed using the Mascot peptide mass fingerprint.

Far-UV Circular Dichroism Spectroscopic Analysis. Circular dichroism (CD) spectropolarimeter (JASCO J-715) measurements using a $0.1 \mathrm{~cm}$ cell were carried out at $0.2-\mathrm{nm}$ intervals and at $25^{\circ} \mathrm{C}$. The $\mathrm{CD}$ spectra of purified recombinant CDX1/2 and HOXD8 (average of 10 scans) were recorded in the 190-260 nm range. A far-UV CD spectrum was obtained at a protein concentration of $0.5 \mathrm{mg} / \mathrm{mL}$ in milli-degrees and converted to molar ellipticity prior to secondary-structural analysis. Calculation of secondarystructural elements was performed using the $\mathrm{CDNN}$ program.

Biacore Biosensor Analysis. Measurements of the apparent dissociation constants $\left(K_{\mathrm{D}}\right)$ between $\mathrm{CDX} 1 / 2$ and HOXD8 were carried out using a Biacore 2000 biosensor (Biosensor, Sweden). HOXD8 $(100 \mu \mathrm{g} / \mathrm{mL}$ in $10 \mathrm{mM}$ sodium acetate, with a $\mathrm{pH}$ of 4.5) was covalently bound to the carboxylated dextran matrix at a concentration corresponding to 1,200 response units (RU) by an amine-coupling method as suggested by the manufacturer. A flow path involving two cells was employed to simultaneously measure the kinetic parameters from one flow cell, containing the HOXD8-immobilized sensor chip to the other flow cell containing an underivatized chip. For kinetic measurements at room temperature, $\mathrm{CDX} 1 / 2$ samples with concentrations ranging from $975-7,800 \mathrm{nM}$ were prepared by dilution in HBS buffer $(150 \mathrm{mM} \mathrm{NaCl}, 3 \mathrm{mM}$ EDTA, $0.005 \%$ surfactant P20, and $10 \mathrm{mM}$ HEPES, with a $\mathrm{pH}$ of 7.4). Each sample was injected along with $50 \mu \mathrm{L}$ of $\mathrm{CDX} 1 / 2$ solution into the flow cells (association phase) at a rate of $10 \mu \mathrm{L} / \mathrm{min}$. Between cycles, the immobilized ligand was regenerated by injecting $30 \mu \mathrm{L}$ of $50 \mathrm{mM} \mathrm{NaOH}$ at a rate $10 \mu \mathrm{L} / \mathrm{min}$.

Differential Scanning Calorimetry (DSC). Differential scanning calorimetric measurements were carried out using a DSC 204 F1 (NETZSCH DSC, USA). Approximately $1 \mathrm{mg}$ of protein was placed in an aluminum pan, which was sealed immediately. The pan was then heated from $-10^{\circ} \mathrm{C}$ to approximately $90{ }^{\circ} \mathrm{C}$ at a rate of $1{ }^{\circ} \mathrm{C} / \mathrm{min}$. An empty pan was used as a reference. The sensitivity was $0.1 \mu \mathrm{w}$, and the sensor time constant was 0.6. A reference of the same state (liquid) was placed in a reference crucible made of aluminum. The onset temperature (Tm), peak transition or denaturation temperature (Td), enthalpy of denaturation $(\Delta \mathrm{H})$, and cooperativity, as represented by the width at half-peak height
$(\Delta \mathrm{T} 1 / 2)$, were computed from thermograms using Universal Analysis Version 3.0.3. The sample was examined twice by repeating the heating-cooling cycles. The sealed pan containing the protein sample and reference was equilibrated.

Fluorescence Spectroscopy. Fluorescence emission spectra were obtained using an Edinburgh (UK) FLS920 Time Correlated Single Photon Counting Spectrometer (TCSPC) with $1 \mathrm{~cm}$ path length cuvettes containing excitation and emission slits $20 \mathrm{~nm}$ in width. The fluorescence emission spectra of CDX1/2 and HOXD8 were obtained in order to identify characteristic chemical structures, namely double bonds and aromatic groups. The emission intensity was recorded at 305-465 $\mathrm{nm}$ with an excitation wavelength of $295 \mathrm{~nm} . \mathrm{CDX} 1 / 2$ and HOXD8, each at a concentration of 5 $\mathrm{uM}$, were preincubated together for $25 \mathrm{~min}$ at $25^{\circ} \mathrm{C}$. All spectra were obtained at a protein concentration $50 \mu \mathrm{g} / \mathrm{mL}$ at $24^{\circ} \mathrm{C}$. Ten spectra of each protein sample were collected, averaged, and subjected to baseline correction by subtracting the buffer spectrum.

Cross-Linking Assay. To determine if the CDX1/2 proteins form monomers or oligomers, cross-linking examination of the truncated CDX1/2 proteins was carried out. Purified CDX1/2 proteins were incubated with $0.001 \%$ glutaraldehyde for $2-5 \mathrm{~min}$ at $37^{\circ} \mathrm{C}$. Cross-linked products were analyzed by $12 \%$ SDS-PAGE using a $200 \mathrm{kDa}$ protein marker.

His-Tagged Pull-Down Assay. For the pull-down experiment, His-tagged fusion protein-immobilized Sepharose beads were prepared. A total of $50 \mu \mathrm{g}$ each of purified GST-CDX1/ 2 and His-tagged HOXD8 was mixed with $50 \mu \mathrm{L}$ of Nimetal chelating affinity resin in binding buffer $\mathrm{A}$ by rotating at $4{ }^{\circ} \mathrm{C}$ for $3 \mathrm{~h}$. The supernatant was removed via centrifugation at $8,000 \mathrm{rpm}$ for $3 \mathrm{~min}$. The beads were then washed three times with buffer A. Each time, the beads were then incubated with wash buffer on a rotator for $3 \mathrm{~min}$ and collected by centrifugation. The beads were then eluted with elution buffer $(50 \mathrm{mM}$ Tris- $\mathrm{HCl}$ with a $\mathrm{pH}$ of 7.5, $200 \mathrm{mM}$ $\mathrm{NaCl}, 1 \mathrm{mM}$ DTT, and $200 \mathrm{mM}$ imidazole), boiled in SDS sample loading buffer for $5 \mathrm{~min}$, and then resolved by performing SDS-PAGE analysis for Coomassie blue staining.

\section{Results and Discussion}

Full-length $\mathrm{CDX} 1$ and $\mathrm{CDX} 2$ proteins contain two domains each. The N-terminal caudal-like activation region (CDX1, amino acids (aa) 13-147; and aa CDX2, 13-180) mediates transcriptional activation, whereas the C-terminal homeobox domain (CDX1, aa 152-216 and CDX2, aa 184248 ) binds to the DNA in a helix-turn-helix (HTH) structure. Caudal-related homeoproteins bind DNA via an AT-rich sequence with a consensus sequence of A/CTTTATA/G. ${ }^{19}$ One mechanism postulated to account for the different effects exerted by CDX1 and CDX2 suggests that they could interact with different functional partners. The CDX1 and CDX2 proteins exhibit extensive sequence similarity in their HDs responsible for DNA-binding (96.6\%), whereas the percentage is lower in the N-terminal (35.5\%) and C- 
terminal domains $(36.5 \%)$ flanking the HD. We previously found that CDX2 binds to HOXD8 in rat gastric tissue cells. $^{20}$ To investigate whether or not the CDX1/2 HDs interact with the HOXD8 HD, recombinant CDX1/2 and HOXD8 were isolated.

The sequence alignments of CDX1 and CDX2 HDs are shown in Figure 1(b). The HDs are completely conserved in CDX1 and CDX2 except for four amino acids in CDX1. CDX1 and CDX2 are structurally related proteins that are highly expressed in the epithelium of the small intestine and the colon. To investigate structural characterization of CDX1 and CDX2 in the HD, the soluble HD CDX1 and

(a)

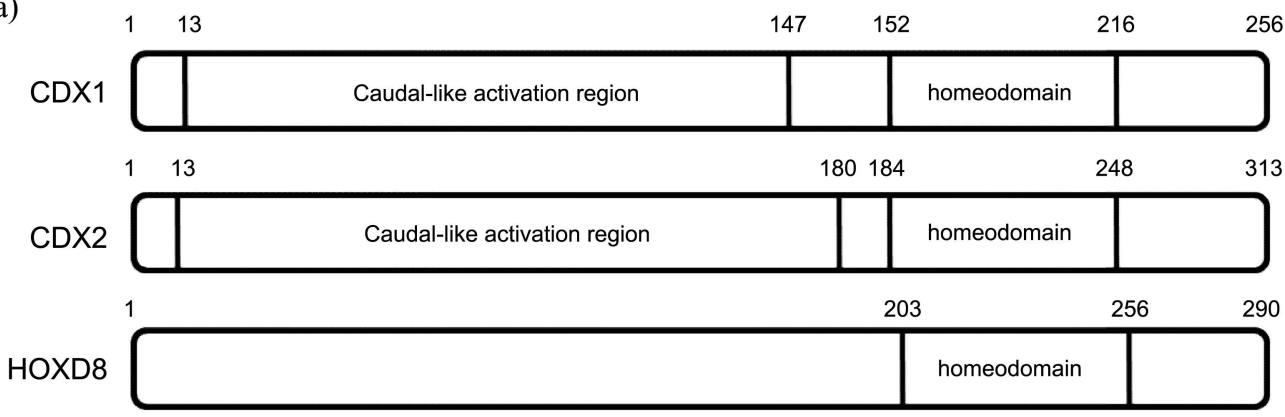

(b)

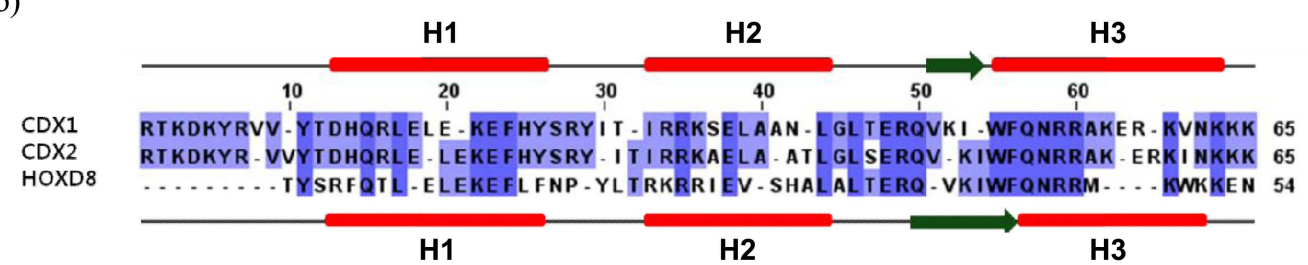

(c)
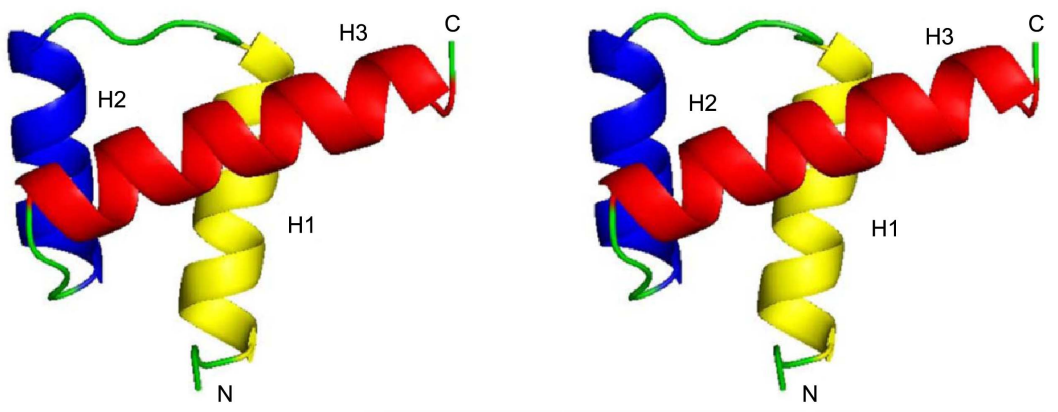

(d)

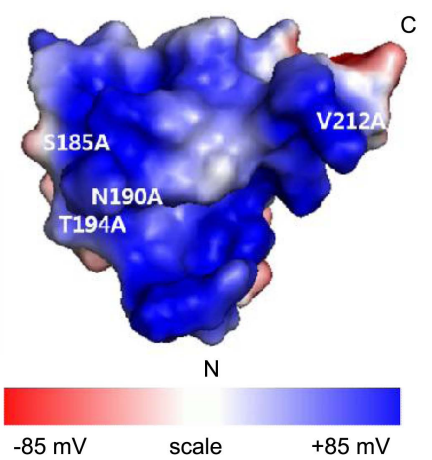

(e)

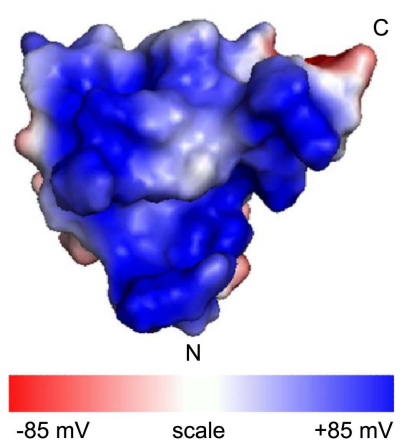

(f)

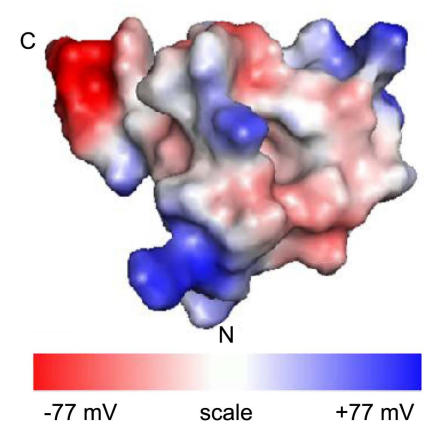

Figure 1. Domain structure, sequence alignment of CDX1/2, and predicted secondary structure of CDX1/2. (a) Schematic diagram showing the domains of CDX1/2 and HOXD8. (b) Sequence alignment of the homeodomains of human CDX1/2 and HOXD8. Residues that are identically conserved in the two species are in blue. The sequences were aligned using Jalview (University of Dundee, Scotland). The secondary structures of CDX1/2 and HOXD8 were predicted. $\alpha$ helices are shown as red ellipses, and $\beta$-sheets as green arrows. Loops are shown as gray lines. (c) A stereoview of the modeled HOXD8 homeodomain is shown. Molecules are shown as ribbon representations in a white window. Blue and red represent positive and negative electrostatic potential, respectively. (d) CDX1 homeodomain, (e) CDX2 homeodomain, and (f) HOXD8 homeodomain are modeled. Molecules are shown as surface representations in a white window. 
CDX2 proteins were purified to homogeneity. To study the binding properties of CDX1 mutants, four proteins (S185A, N190A, T194A, and V212A) were purified and analyzed.

Truncated HOXD8 (HD: 203-256) protein was expressed mainly in soluble form in E. coli BL21(DE3) at $25^{\circ} \mathrm{C}$ (Fig. 2). Isolated His-tagged HOXD8 has been observed to have a molecular weight of approximately $9 \mathrm{kDa}$. We obtained HOXD8 soluble protein at a final concentration of $2 \mathrm{mg} / \mathrm{mL}$. The soluble CDX1/2 and HOXD8 proteins were purified to homogeneity and their identities determined by Western blot analysis (Fig. 2(d)).

In this study, we found a structurally conserved protein in the HDs of CDX1/2 and HOXD8. The result of an Expert Protein Analysis System (EXPASY) search with the PDB revealed that one reference protein, having a structure including the Antennapedia homeodomain-DNA complex (PDB ID: 9ant), had 63-70\% sequence similarity to the HDs of CDX1/2 and HOXD8, respectively. Structurally conserved regions among $\mathrm{CDX} 1 / 2, \mathrm{HOXD} 8$, and the template were determined by multiple sequence alignment from CLUSTAL W (Fig. 1(b)). The CDX1/2 and HOXD8 models were constructed using SWISS-MODEL software, a program designed for relative protein structure modeling (Fig. 1(c-f)). ${ }^{21}$

(a)

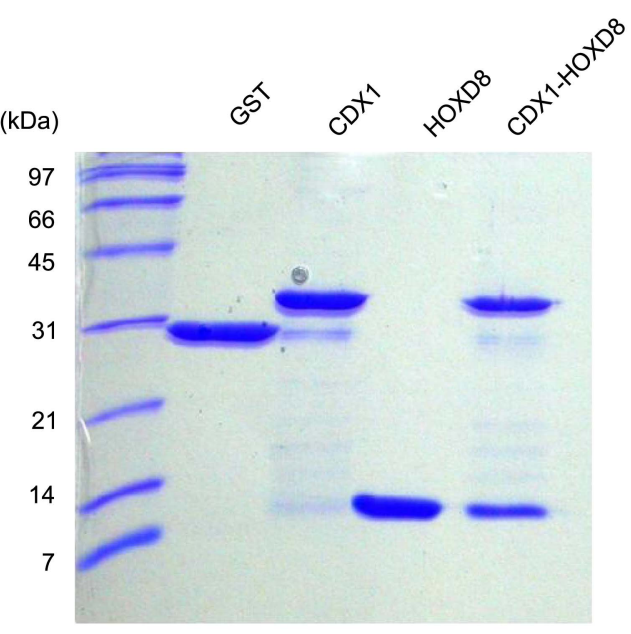

(c)

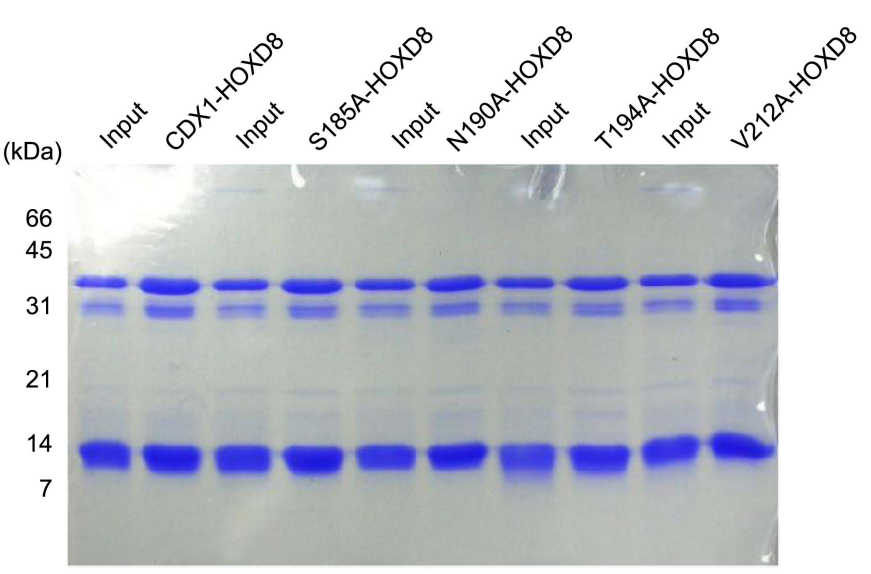

His-tagged HOXD8 fusion protein effectively pulled-down both CDX1 and CDX2 HDs (Fig. 2(a) and (b)). These results indicate that $\mathrm{CDX} 1$ and $\mathrm{CDX} 2$ interact with $\mathrm{HOXD} 8$ in vitro. Next, we constructed the CDX1 mutants S185A, N190A, T194A, and V212A. The four different mutant proteins still bound to HOXD8 as effectively as wild-type CDX1 (Fig. 2(c)). These results indicate that conformational changes are present in that $\mathrm{N}$-terminal region, which might cause differences in function between CDX1 and CDX2.

To further investigate the interaction between CDX1/2 and HOXD8, the fluorescence emission spectra of purified CDX1/2 and HOXD8 were measured, and the $\lambda_{\max }$ curve was detected at $330 \mathrm{~nm}$ (Fig. 3(a) and (b)). The spectrum of the CDX1 (152-216)-HOXD8 (203-256) complex at $330 \mathrm{~nm}$ was slightly higher than that of HOXD8 alone. On the other hand, the spectrum of the CDX2 (184-248)-HOXD8 (203256) complex was slightly lower than that of HOXD8 alone. Both spectra of the CDX1/2-HOXD8 complex were lower than that of simply combining CDX1/2 and HOXD8. The fluorescence intensities were approximately 1,400 $\mathrm{N}$ for CDX1, 1,900 $\mathrm{N}$ for CDX2, and $2600 \mathrm{~N}$ for HOXD8. The interaction is most likely accompanied by significant conformational changes in either one or both proteins and is likely

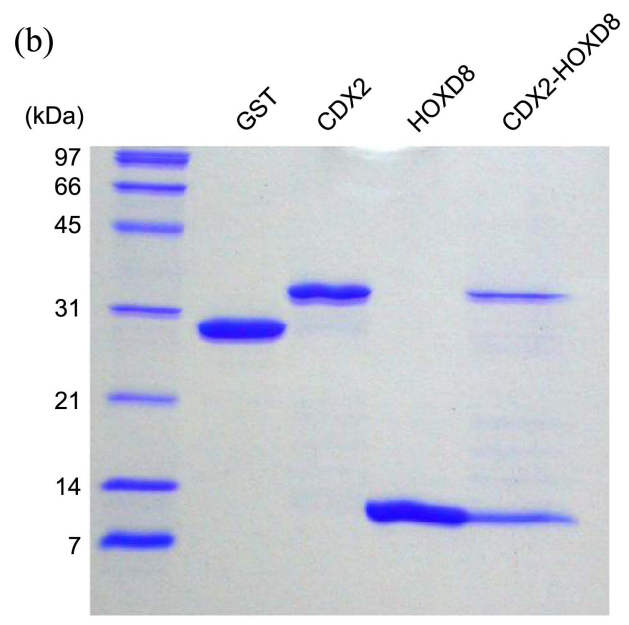

(d)

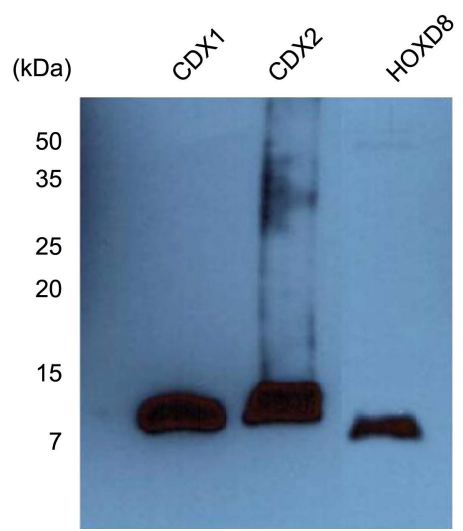

Figure 2. His-tagged pull-down assay for the CDX1/2-HOXD8 complex. Binding of CDX1/2 and HOXD8 was detected by $15 \%$ sodium dodecyl sulfate polyacrylamide gel electrophoresis (SDS-PAGE). (a) and (b) Results of the His-tagged pull-down assay using His-HOXD8 and GST-CDX1/2 in vitro. (c) Results of the His-tagged pull-down assay for GST-CDX1 (S185A, N190A, T194A, and V212A) and HOXD8 in vitro. (d) Western blot analyses of CDX1 and CDX2. Lane 1: CDX1; Lane 2: CDX2; Lane 3: HOXD8. 

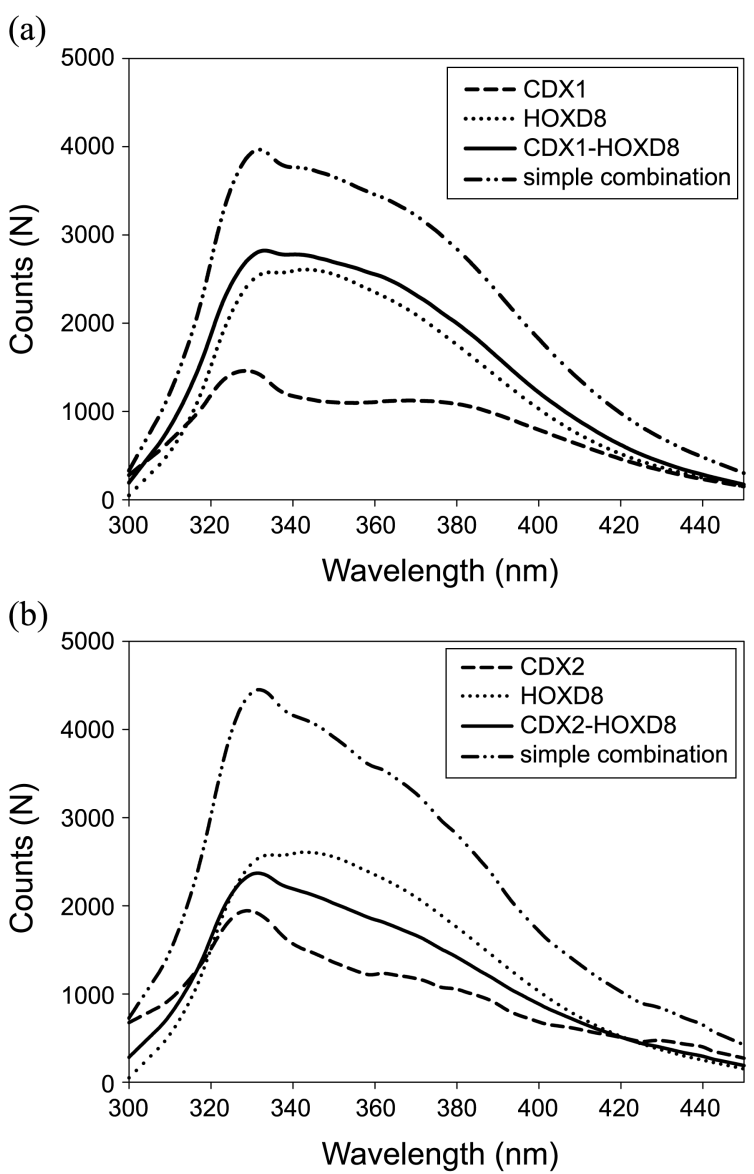

Figure 3. $(\mathrm{a}$ and $\mathrm{b})$ Fluorescence analysis of $\mathrm{CDX} 1 / 2$ binding to HOXD8. Fluorescence spectra of the CDX1/2-HOXD8 complex and of each individual protein are shown.

mediated since the residues of the aromatic groups are buried within the $3 \mathrm{D}$ protein structure. Further, the less rigid, hydrophobic environment required for the conformational changes of CDX1/2 and HOXD8 can be initiated by a decrease in fluorescence intensity. CDX1 showed significant affinity for HOXD8, whereas CDX2 showed weak affinity for HOXD8. Taking our findings together, it was concluded that both CDX1 and CDX2 HD regions can interact with HOXD8, although CDX1 interacts more strongly.

The folding properties of both CDX1/2 and HOXD8 were characterized by CD spectroscopy. To investigate the secondary structural elements of CDX1/2 and HOXD8, far-UV CD spectra were recorded and analyzed (Fig. 4(a)). The secondary structural elements and conformational properties of CDX1/2 were fairly different from those of HOXD8. The CD spectrum of purified HOXD8 showed two negative peaks at approximately 208 and $225 \mathrm{~nm}$, characteristic of an alpha-helical spectrum, whereas the CD spectrum of purified CDX1 and CDX2 showed one negative peak at approximately $208 \mathrm{~nm}$. The CD signal was converted to mean residue ellipticity (MRE) using the following equation: $\mathrm{MRE}=\theta /(10$. $l \cdot \mathrm{C} \cdot \mathrm{N}_{\mathrm{A}}$ ), where $\theta$ is the ellipticity (in mdeg), $l$ is the length of the light path in centimeters, $\mathrm{C}$ is the molar concentration of the protein, and $\mathrm{N}_{\mathrm{A}}$ is the number of protein residues.

The HOXD8 HD was treated with a cross-linking reagent (a)
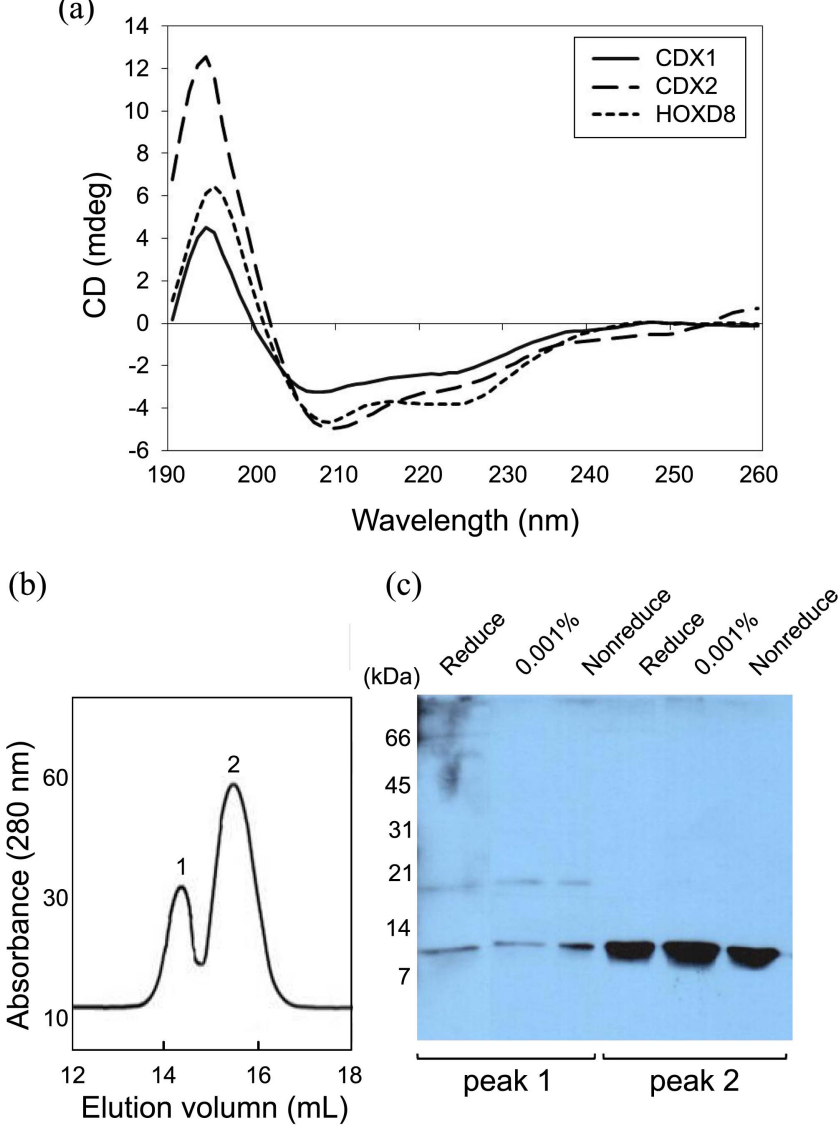

Figure 4. Circular dichroism (CD) spectra were measured from 190-260 nm, and the CD signals were merged into CDNN. The experiments were carried out using a JASCO J-715 spectropolarimeter with a $0.1 \mathrm{~cm}$ cell at $0.2 \mathrm{~nm}$ intervals and $25{ }^{\circ} \mathrm{C}$. These spectra were the results of 10 scans. (a) Far-UV CD spectra of CDX1/2 and HOXD8. (b) Analysis of cross-linking experiments showing separated fractions of the proteins. Peak 1, purified HOXD8 (dimer); peak 2, purified HOXD8 (monomer) eluted from the size-exclusion column. Purified HOXD8 was cross-linked with glutaraldehyde and analyzed by Western blot analysis. Lane 1: (reduced); lane 2: 0.001\% glutaraldehyde; lane 3: (nonreduced); lane 4: reduced; lane 5: $0.001 \%$ glutaraldehyde, and lane 6: nonreduced.

$0.001 \%$ glutaraldehyde, in buffer $\mathrm{A}$. The separated fraction of the HOXD8 HD was shown in two peaks (Fig. 4(b)). While the dimer band was identified in the first peak, the monomer bands were detected in the other peaks. Western blot analysis of the cross-linked product revealed a dimeric His-tagged HOXD8 HD band of about 18 kDa (Fig. 4(c)). These experiments provide evidence that HOXD8 HD could exist either as a monomer or dimer in solution. The HDs frequently bind to DNA as a monomer, in contrast to prokaryotic DNA-binding proteins containing a helix-turn-helix motif, which usually bind as dimers. HOX/PBX dimers have significantly greater binding affinity and specificity for target DNA sequences than HOX monomer alone. ${ }^{22}$

The binding affinities of CDX1/2 for HOXD8 were also estimated by surface plasmon resonance spectroscopy (Biacore; Fig. 5(a) and (b)). Sensorgrams of CDX1/2 bind- 
(a)

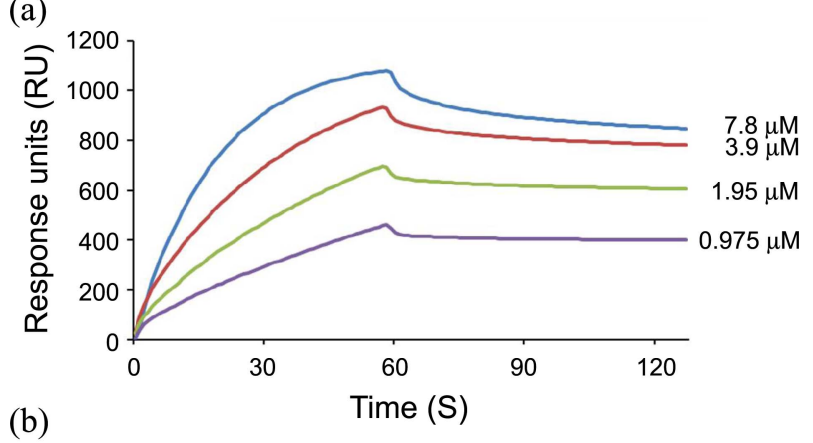

(b)

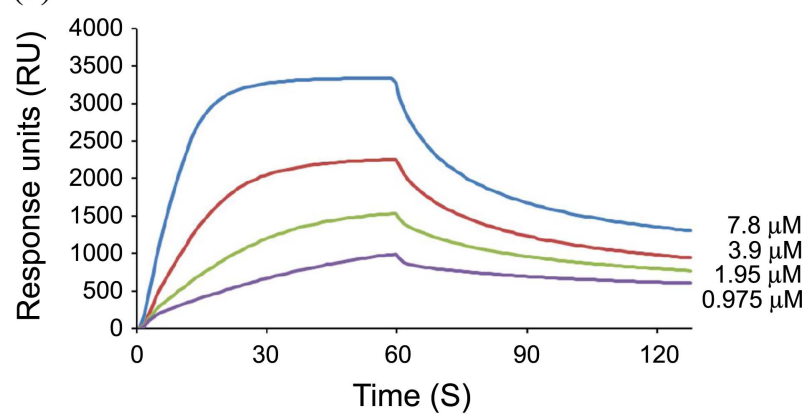

Figure 5. ( $\mathrm{a}$ and $\mathrm{b}$ ) Biacore biosensor analysis of $\mathrm{CDX} 1 / 2$ binding to HOXD8 at $25{ }^{\circ} \mathrm{C}$. CDX1/2 sensorgrams for $975,1950,3900$, and $7800 \mathrm{nM}$ are shown.

Table 1. Kinetic parameters of binding of CDX1/2 to HOXD8 ${ }^{a}$

\begin{tabular}{lcccc}
\hline & $\begin{array}{c}\text { Concs of } \\
\text { analyte }(\mathrm{nM})\end{array}$ & $k_{\mathrm{a}}\left(\mathrm{M}^{-1} \mathrm{~s}^{-1}\right)$ & $k_{\mathrm{d}}\left(\mathrm{s}^{-1}\right)$ & $K_{\mathrm{D}}(\mathrm{M})$ \\
\hline CDX1 & & & & \\
& 7800 & $1.13 \times 10^{5}$ & $4.36 \times 10^{-4}$ & $3.85 \times 10^{-9}$ \\
& 3900 & $1.18 \times 10^{5}$ & $2.86 \times 10^{-4}$ & $2.42 \times 10^{-9}$ \\
& 1950 & $9.20 \times 10^{4}$ & $1.62 \times 10^{-4}$ & $1.76 \times 10^{-9}$ \\
& 975 & $4.77 \times 10^{4}$ & $3.13 \times 10^{-5}$ & $6.56 \times 10^{-10}$ \\
$K_{\mathrm{D}}(\mathrm{nM})_{\text {avg }}$ & & & & 2 \\
$\mathrm{CDX} 2$ & & & & \\
& 7800 & $2.19 \times 10^{5}$ & $5.34 \times 10^{-3}$ & $2.43 \times 10^{-8}$ \\
& 3900 & $1.79 \times 10^{5}$ & $5.75 \times 10^{-3}$ & $3.21 \times 10^{-8}$ \\
& 1950 & $8.84 \times 10^{4}$ & $4.96 \times 10^{-3}$ & $5.61 \times 10^{-8}$ \\
$K_{\mathrm{D}}(\mathrm{nM})_{\text {avg }}$ & 975 & $3.75 \times 10^{4}$ & $3.30 \times 10^{-3}$ & $8.81 \times 10^{-8}$ \\
\hline
\end{tabular}

${ }^{a}$ The association rate constant $\left(k_{\mathrm{a}}\right)$ was determined from a plot of $\operatorname{In}[\operatorname{Abs}(\mathrm{d} R / \mathrm{d} t)]$ versus time, where $R$ is the intensity of the surface plasmon resonance signal at time $t$. The dissociation rate constant $\left(k_{\mathrm{d}}\right)$ was determined from a plot of $\operatorname{In}\left(R_{0} / R\right)$ versus time, where $R_{0}$ is the resonance signal intensity at time zero. The apparent $K_{\mathrm{D}}$ was calculated from the kinetic constants: $K_{\mathrm{D}}(\mathrm{M})=k_{\mathrm{d}} / k_{\mathrm{a}}$.

ing to HOXD8 were used to calculate kinetic binding constants. Background sensorgrams were then subtracted from the experimental sensorgrams to yield representative specific binding constants. We found that HOXD8 physically bound both CDX1 and CDX2 with an apparent $K_{\mathrm{D}}$ of $2 \mathrm{nM}$ for CDX1 and a $K_{\mathrm{D}}$ of $50 \mathrm{nM}$ for CDX2.

In this study, we carried out the purification and characterization of truncated CDX1/2 and HOXD8 proteins in $E$. coli. Furthermore, by performing a series of biochemical and biophysical measurements, we confirmed that $\mathrm{CDX} 1 / 2$ interacts with HOXD8 both in vivo and in vitro. These results provide important information on the development of CDX1/2 for structural study, binding activity of CDX1/2 HD to HOXD8 $\mathrm{HD}$, and protein-protein interactions involving caudal-related homeodomain transcription factor. Intriguingly, the HD of CDX1 bound with higher affinity to the HD of HOXD8 than that of CDX2. Therefore, this study provides important clues about the structural interactions of the CDX1/2 and HOXD8 proteins.

Acknowledgments. This study was supported by the Basic Science Research Program through the National Research Foundation of Korea (NRF) and by the Ministry of Education, Science and Technology, with grant 2010-0022004 to author S.B.J. and grant 2010-0024463 to author M.S.J.

\section{References}

1. McGinnis, W.; Krumlauf, R. Cell 1992, 68, 283-302.

2. Ferrier, D. E.; Minguillon, C. Int. J. Dev. Biol. 2003, 47, 605-611.

3. Yamamoto, M.; Takai, D.; Yamamoto, F. Gene Expr. 2003, 11, 199-210.

4. Takahashi, Y.; Hamada, J.; Murakawa, K.; Takada, M.; Nogami, I.; Hayashi, N.; Nakamori, S.; Monden, M.; Miyamoto, M. Exp. Cell. Res. 2004, 293, 144-153.

5. Maroulakou, I. G.; Spyropoulos, D. D. Anticancer Res. 2003, 23, 2101-2110.

6. Subramanian, V.; Meyer, B.; Evans, G. S. Differentiation 1998, 64, $11-18$.

7. Suh, E.; Chen, L.; Taylor, J.; Traber, P. G. Mol. Cell. Biol. 1994, 14, 7340-7351.

8. Troelsen, J. T.; Mitchelmore, C.; Spodsberg, N., Jensen, A. M.; Noren, O.; Sjostrom, H. Biochem. J. 1997, 322, 833-838.

9. Taylor, J. K.; Boll, W.; Levy, T.; Suh, E. R.; Siang, S.; Mantei, N.; Traber, P. G. DNA Cell Biol. 1997, 16, 1419-1428.

10. Colnot, S.; Romagnolo, B.; Lambert, M.; Cluzeaud, F.; Porteu, A.; Vandewalle, A.; Thomasset, M.; Kahn, A.; Perret, C. J. Biol. Chem. 1998, 273, 31939-31946.

11. Friedmann, Y.; Daniel, C. A.; Strickland, P. ; Daniel, C. W. Cancer Res. 1994, 54, 5981-5985.

12. Vider, B.; Zimber, A.; Hirsch, D.; Estlein, D.; Chastre, E.; Prevot, S.; Gespach, C.; Yaniv, A.; Gazit, A. Biochem. Biophys. Res. Commun. 1997, 232, 742-748.

13. Vider, B.; Zimber, A.; Chastre, D. E.; Gespach, G. C.; Halperin, M.; Mashiah, P.; Yaniv, A.; Gazit, A. Biochem. Biophys. Res. Commun. 2000, 272, 513-518.

14. Lorentz, O.; Duluc, I.; Arcangelis, A. D.; Simon-Assmann, P.; Kedinger, M.; Freund, J. N. J. Cell. Biol. 1997, 139, 1553-1565.

15. Soubeyran, P.; Andre, F.; Lissitzky, J. C.; Mallo, G. V.; Moucadel, V.; Roccabianca, H. Rechreche, M.; Marvaldi, J.; Dikic, I.; Dagorn, J. C. Gastroenterology 1999, 117, 1326-1338.

16. Lickert, H.; Domon, C.; Huls, G.; Wehrle, C.; Duluc, I.; Clevers, H.; Meyer, B. I.; Freund, J. N.; Kemler, R. Development 2000, 127, 3805-3813.

17. Blache, P.; van de Wetering M.; Duluc, I.; Domon, C.; Berta, P.; Freund, J. N.; Clevers, H.; Jay, P. J. Cell. Biol. 2004, 166, 37-47.

18. Niwa, H.; Toyooka, Y.; Shimosato, D.; Strumpf, D.; Takahashi, K.; Yagi, R.; Rossant, J. Cell 2005, 123, 917-929.

19. Margalit, Y.; Yarus, S.; Shapira, E.; Gruenbaum, Y.; Fainsod, A. Nucleic Acids Res. 1993, 21, 4915-4922.

20. Jeong, M. S.; Hwang, E. Y.; Kim, H. T.; Yoo, M.-A.; Jang, S. B. J. Microbiol. Biotechnol. 2009, 19, 1557-1564.

21. Guex, N.; Peitsch, M. C. Electorphoresis 1997, 18, 2714-2723.

22. Shen, W. F.; Rozenfeld, S.; Lawrence, H. J.; Largman, C. J. Biol. Chem. 1997, 272, 8198-8206. 